\title{
How Leaders Generate Meanings For Monetary Rewards
}

\author{
Yufan Shang, Xi'an Jiaotong University, P. R. China \\ Jun Xu, Xi'an Jiaotong University, P. R. China \\ Fuli Li, Xi'an Jiaotong University, P. R. China \\ Xinyu Zhao, Xi'an Jiaotong University, P. R. China \\ Haiyun Li, Xi'an Jiaotong University, P. R. China
}

\begin{abstract}
Scant research has focused on how to increase the value of monetary rewards when they are delivered by leaders to employees. Drawing upon the perspectives of sensegiving and sensemaking, this study explores how leaders generate meanings of monetary rewards perceived by employee recipients in organizational settings. Using a qualitative method design and analyzing qualitative data from 291 incidents, we found that in the distribution process of monetary rewards, sensemaking of employees included strong and weak instrumental meanings as well as symbolic meanings. The results show that leaders adopted a set of sensegiving strategies in distributing monetary rewards including emphasizing money gain/loss and utility, providing feedback, valuing employees, orienting toward the future, guiding values, and publicizing. In the presence of leader's sensegiving, employee recipients endorsed more positive symbolic meanings of monetary rewards (i.e., recognition and respect). Our research offers a richer view of the role of leader's sensegiving in making monetary rewards gain more value through employees' sensemaking, and enriches understanding of monetary rewards, leadership, sensegiving and sensemaking.
\end{abstract}

Keywords: Monetary Rewards; Symbolic and Instrumental Meanings; Sensegiving; Sensemaking

\section{INTRODUCTION}

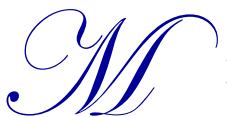

onetary rewards are the money given to employees as a material return for their work. They are the pecuniary part of employee compensation in general regardless of the forms or types of money, such as bonuses, rewards, and cash gifts. This has received great attention for decades because of their key role in motivating and rewarding employees in organizations (Jenkins, Jr., Mitra, Gupta \& Shaw, 1998; Lawler, 1971). However, empirical studies on the effects of offering monetary rewards for recipient motivation and performance have been found to be inconsistent (Beer et al. 2004). To untangle the complexity of the impact of monetary rewards, some scholars suggested that their effects might be contingent on how the individual recipients interpret the meanings of monetary rewards provided (Mickel \& Barron, 2008; Thierry, 1992). Symbolic meanings of monetary rewards have been found to exert a positive impact on recipients' job performance (Hakonen, Hulkko \& Maaniemi, 2006) and pay satisfaction (Salimäki, Hakonen \& Heneman, 2009). Therefore, monetary rewards received not only have economic or instrumental meanings but also carry important symbolic meanings for assessing one's self-worth and status. However, scant research has focused on how monetary rewards can lead to and engender symbolic meanings. Addressing this research gap is attractive for practitioners who are attempting to search for best practices and identifying creative ways to maximize the value of money.

The present study explores how employee recipients perceive meanings of monetary rewards by focusing on the leaders' statements and behaviors in its distribution process. The role of leaders in the distribution process was focused upon due to three reasons. First, the manner in which money was distributed affected the symbolic meaning associated with the monetary rewards. Second, leaders played a critical role in such processes as they possessed the power to control and influence the distribution process. Third, leaders were responsible for communicating with their employees about their work and organizational information, such as decision-making, procedures, and policies (Child, 2015; Mickel \& Barron, 2008). If leaders could send suitable, sufficient, and consistent messages about the distributed 
monetary rewards, the employee recipients are likely to have accurate understanding and construct corresponding meanings about the monetary rewards received.

For realization of the research objective, the perspective of sensegiving (Gioia \& Chittipeddi, 1991) was investigated to know how leaders constructed and gave meanings to the distribution process of monetary rewards. The perspective of sensemaking (Weick, 1995) was adopted to explore how the employee recipients interpreted the meanings of monetary rewards provided by leaders. Sensegiving represents a sensegiving process of "attempting to influence the sensemaking and meaning construction of others toward a preferred redefinition of organizational reality" (Gioia \& Chittipeddi, 1991, p. 442). Leaders' sensegiving involved leader statements and behaviors in distributing monetary rewards that would affect employee understanding of the meanings of monetary rewards.

The remainder of this research paper is structured as follows. First, a brief review of monetary rewards and meanings of pay, sensemaking, and sensegiving is presented. Second, research questions and a discussion of the link between leader sensegiving in distributing monetary rewards and employee sensemaking in interpreting the monetary rewards received are given. Third, the field data collected and the qualitative research method used for addressing the research questions are clarified. Finally, the theoretical and managerial implications, future research directions and limitations of the study are discerned, before a conclusion is reached.

\section{THEORETICAL BACKGROUND AND RESEARCH QUESTION DEVELOPMENT}

\section{Effects of Monetary Rewards on Employee Outcomes}

Monetary rewards have been argued to exert a significant impact on employee behavior and performance (Jenkins Jr. et al., 1998). Money in the form of bonuses, rewards, and cash gifts is viewed as a "crucial and powerful motivation tool" (Furnham \& Argyle, 1998, p. 204), which is distributed to motivate, retain, attract, and recognize employees. However, past empirical findings on the effects of monetary rewards have been found to be inconsistent and controversial (Deci, Koestner \& Ryan, 1999). Kosfeld, Neckermann and Yang (2014) reported that monetary incentives significantly increased performance and worked well and performed robust under both high and low perceived job meaning conditions. However, it has been found that monetary rewards do not always lead to desirable outcomes (Aguinis, Joo \& Gottfredson, 2013). They may sometimes fail to motivate (Beer et al., 2004) and even lead to counterproductive outcomes, such as financial misrepresentation activities (Harris \& Bromiley 2007). Financial rewards could also create lowered self-perceptions of autonomy (Drake, Wong \& Salter, 2007), and decrease trust and cooperation (Christ, Sedatole, Towry \& Thomas, 2008).

The mixed effects of monetary rewards could be explained by the meanings that employees attach to such monetary rewards (Child, 2015; Thierry, 1992). Money is not only instrumental in fulfilling material desires but also has symbolic meanings (Child, 2015). This idea is consistent with the reflection theory of pay (Thierry, 1992), which states that pay has four dimensions of meanings, namely, motivational properties (a means for achieving important personal goals), relative position (providing performance feedback on their competence in relation to that of their coworkers), control (position in the organizational hierarchy), and spending (goods and services to be purchased). The first three dimensions reflect the symbolic meanings of pay, which are central to individual self-concept (Thierry, 1992). Research provides empirical support for the positive impact of the symbolic meanings of monetary rewards. For instance, the symbolic meanings of pay, including relative position and control, have been found to be positively related to pay satisfaction (Salimäki et al. 2009) and performance (Hakonen et al. 2006). In addition, Mitchell and Mickel (1999) concluded that achievement, recognition, status and respect are associated with the symbolic meanings of pay.

Therefore, it is important to find out how individuals develop perceptions of the symbolic meanings of monetary rewards. Recent studies provided initial attempts to address this question. Child (2015) highlighted that reward can have greater symbolic meanings that depends on "who distributes the monetary reward, why it is given, how it is awarded, and who receives it" (p. 192). When leaders set up clear goals, align individual goals with the organizational strategies, and clearly deliver organizational goals, employees positively interpret the organizational reward system and enhance their satisfaction of the pay (Salimäki et al. 2009). Moreover, Nelms and Maurer (2014) proposed that money can have strong symbolic value and the meaning of money is likely to be re-interpreted by people in certain 
situations, for e.g., after receiving money, after spending money, and after being exposed to money. Thus, the perception and interpretion of employees after receiving monetary rewards could also have impact on the generation of the meaning of that money.

\section{Leader's Sensegiving and Employee's Sensemaking}

To analyze the dynamic processes between leaders as money distributors and employees as money recipients, the perspectives of sensegiving (Gioia \& Chittipeddi, 1991) and sense making (Weick, 1995) were adopted. The process model of identification (Ashforth, Harrison \& Corley, 2008) could demonstrate the sensegiving and sensemaking within organizational contexts to some extent. This model depicted unfolding of an organizational identification and defined it as "a perceived oneness with the organization, necessarily implicating one's self-concept" (Ashforth et al. 2008 , p. 333). The top-down and bottom-up approaches of the model interplays between organization or leader as a representative of the organization, and individuals. The top-down process described the organizational use of sensegiving (i.e., organizational communication strategies) to guide the meaning construction of employees and encourage identification. The bottom-up process reflected how an individual uses sensemaking to interpret the organization's sensegiving, derive meanings from their experience, and enact their identity to negotiate organizational identification. Scholars have applied both sensegiving and sensemaking to investigate the organizational context characterized by uncertainty or ambiguity (Weick, 1995). However, limited research has been done to explore the interplay between leaders and employees, especially in the monetary reward distribution process.

\section{Sensegiving and Its Application}

Sensegiving is an interpretive process (Gioia \& Chittipeddi, 1991) in which sense-givers apply persuasive or evocative statements to explain certain events to influence the understanding of the sense-receivers of these events. People holding different organizational positions, including top-level leaders, middle-level managers, and employees, can be viewed as appropriate sense-givers (Gioia \& Chittipeddi, 1991). As important sense-givers in organizations, leaders are motivated to shape the sensemaking processes of organizational members and seek their support for the major organizational change (Gioia \& Chittipeddi, 1991). They could make sensegiving in different types of contexts (i.e., when leaders design income plan, make key appointments, execute pay, and contract reviews) (Maitlis \& Lawrence, 2007). Meanwhile, in order to achieve desirable sensegiving aims, leaders need to possess relevant expertise to enable recipients to understand well (Maitlis \& Lawrence, 2007). Thus, leaders may exert great influence on how employee recipients interpret monetary rewards. Moreover, different sensegiving strategies taken by leaders may bring about various sensemaking results of employees. Unfortunately, there is scant research that systematically explores how leaders, as an influential sense-giver, affect the generation of meanings of monetary rewards when distributing them to employee recipients.

\section{Sensemaking and Its Application}

As a response to sensegiving, sensemaking refers to the ongoing and retrospective process in which individuals interpret and construct their surrounding realities (Weick, 1995). Sensemaking not simply interprets but involves the active construction of events and frameworks for understanding (Maitlis \& Christianson, 2014). Sensemaking occurs when people are confronted with ambiguous or confusing issues or events (Maitlis \& Christianson, 2014; Weick, 1995), which is primarily triggered by cues in times of crisis or puzzlement. There is a consensus that when organizational individuals encounter ambiguity or uncertainty, they are motivated to clarify what is going on by extracting and interpreting cues from environment (Maitlis \& Christianson, 2014).

In the context of distribution process, it is argued that employees may encounter ambiguity or equivocality due to lack of knowledge on rewards system. It is highly recommended that firms should inform employees about the design and purposes of rewards plans. When receiving monetary rewards, employees might wonder "How my rewards are determined?" and "Is my organization/supervisor satisfied with my performance?" Hence, the employees seek for cues to construct plausible accounts of monetary rewards. This process has been described either individually or socially. Although sensemaking is given by individuals, they cannot make sense of cues that are received isolated from their surrounding environments. Individuals are indeed embedded in a social context where their thoughts, feelings, and behaviors are influenced by the actual, imagined, or implied presence of others. Leaders, as a critical 
social context, can affect employees' perceptions, thoughts, and behaviors. When leaders engage in sensegiving and interact with employees in the distribution process, employees actively select cues from their leader's statements and behaviors to construct meanings of monetary rewards. However, little research has been attempted to identify what kinds of meanings employee would perceive towards monetary rewards distributed by his/her leader.

\section{Research Questions}

In order to fill the research gaps mentioned above, the two research questions have been proposed: "What types of sensegiving statements and behaviors do leaders use to influence employees' perception of monetary rewards in the distribution processes of such rewards?" and "What meanings do employee recipients generate in the sensemaking of monetary rewards offered by leaders during the distribution processes?" The process model of identification (Ashforth et al. 2008) and its two processes were adopted to answer these research questions as discussed previously.

\section{METHODS}

As the qualitative approach was suited for research on an unknown concept or phenomenon, we adopted this approach to address the research questions that are exploratory. Critical Incident Technique (CIT) was used for the initial categories of respondents' descriptions and content analysis was conducted for further classification of data into descriptive categories.

\section{Sample and Procedures}

Twenty employees from a large telecommunication firm were randomly selected and divided into two focus groups. These participants had various levels of working experience and had experience of receiving monetary rewards. Each group was interviewed about their past experiences in the distribution processes of monetary rewards and their feelings about the monetary rewards received. The reported experiences may be roughly divided into two typical categories, namely pleasant and unpleasant. For CIT approach, two extreme incidents, as pleasant and unpleasant experiences, were identified as the critical incidents to further answer the research questions.

To gather sufficient critical incidents, open-ended questions were sent out to 170 MBA students of a top university, located in the northwest province of China. All the respondents were adults with working experience and reported that they had at least one personal experience in receiving monetary rewards provided by their leaders, so they had their own understanding or perceptions about their leader's behaviors and statements during the distribution process. Before answering, they were provided with specific instructions.

The two open-ended questions were presented to the respondents who were required to answer each independently within 30 minutes:

Question I: Please describe a pleasant experience of receiving monetary rewards from your leader.

(1) Why did you feel pleasant about the monetary rewards?

(2) What did your leader say and do in the distribution process?

(3) How did you perceive the monetary rewards?

Question II: Please describe an unpleasant experience of receiving monetary rewards from your leader.

(4) Why did you feel unpleasant about the monetary rewards?

(5) What did your leader say and do in the distribution process?

(6) How did you perceive the monetary rewards?

Finally, 166 out of 170 distributed questionnaires were returned (98\% response rate). Six cases with a large amount of missing data were deleted. The final sample included 160 usable informants. Among them, $61.9 \%$ were male, $40.6 \%$ had an organizational tenure between five to ten years, and $35.6 \%$ were first-line managers. 


\section{Data Analysis}

In total, the data analysis included three stages.

Stage 1: Selecting the critical incidents.

CIT was adopted to identify the sensegiving statements and behaviors of leaders and the sensemaking process of employees. It provides a rich source of data by inviting respondents to recall the most impressive incidents they experienced and use their own terms and language to organize their ideas. As a widely used method for enriching unknown knowledge of real-world phenomena, CIT is exploratory in nature and involves the use of critical incidents to analyze human behaviors (Edvardsson, 1992).

In this study, about 291 valid incidents were screened out. All incidents were converted into electronic documents and grouped into pleasant vs. unpleasant. The criterion for categorization was based on respondents' description of the events and their attributions for why the incidents they experienced were pleasant or unpleasant. Independent judgment was conducted on the descriptions of leaders' behaviors and statements in the coded incidents for further identification. The results showed that inter-judge agreement between each pair was satisfactory, 0.92, 0.91, and 0.90, respectively, exceeding the cutoff value of 0.85 (Kassarjian, 1977) for content analysis. Taking the two extreme scenarios (pleasant vs. unpleasant) and leader sensegiving (with vs. without) into consideration, the critical incidents were divided into four categories: a) pleasant distribution processes with leader's sensegiving, b) pleasant distribution processes without leader's sensegiving, c) unpleasant distribution processes with leader's sensegiving, and d) unpleasant distribution processes without leader's sensegiving. The numbers of valid cases across these four categories were 91, 72, 38, and 90 , respectively.

For further classification and analysis of these critical incidents, the content analysis (Gremler, 2004), and the inductive and deductive approaches were used (Elo \& Kyngäs, 2008). The adoption of inductive or deductive approach is determined by the purpose of analysis. If there is not enough prior knowledge about one phenomenon or if the knowledge is fragmented, the inductive approach is recommended. If there is enough extant knowledge on the phenomenon, the deductive approach is recommended. Thus, the other two stages were as following:

Stage 2: Identifying leader's sensegiving during distribution process of monetary rewards.

As sensegiving strategies of leaders used in the distribution were rarely known, the inductive, exploratory approach was adopted. The data was coded without any pre-set concepts that followed three steps. First, the first-order concepts (Gioia, Corley \& Hamilton, 2013) were identified, which provided simple descriptive labels for leader's sensegiving. Following the approach of line-by-line coding of transcripts (Charmaz, 2014), the texts of selected critical incidents were literally open-coded into 129 items with concise descriptions by three members of the research team independently. Inter-judge agreement was satisfactory (0.89).

Next, the first-order concepts were incorporated into a list of second-order themes, representing the abstract descriptions of sensegiving strategies. We conceptualized the meaning layers of these 129 items and labeled similar clusters with the same code. Accordingly, 13 second-order themes were generated. Similarly, the second-order themes were generated with satisfactory inter-judge agreement $(0.90)$.

Finally, these 13 second-order themes were abstracted into seven aggregated dimensions, providing more comprehensive and synthetical core categories. Independent judgment on the classification results was made by an external expert, and a final consensus was reached. Saturation of categories was well-examined as well.

Stage 3: Identifying employee's sensemaking during distribution process of monetary rewards.

The deductive analytical procedures suggested by Elo and Kyngäs (2008) were used to analyze employee's sensemaking of monetary rewards. After the analysis, the next step was to develop a categorization matrix (either a structured or unconstrained matrix), and code the data accordingly. The unconstrained categories scheme allowed data coding according to the scheme and generated codes following the principles of inductive content analysis. In parallel, 
an unconstrained categories scheme was generated based on earlier work to capture employee's sensemaking of monetary rewards as much as possible. In accordance to prior research, the main categories consisted of instrumental and symbolic meanings of monetary rewards. According to Mickel and Barron (2008), the instrumental meanings included strong and weak instrumentality of money as subcategories.

All the relevant quotes were coded from the descriptions, perceptions, and evaluations of monetary rewards with the qualitative analysis software ATLAS.ti until the consensus was reached. The descriptions were coded in case of emergence of a new subcategory. Inter-judge agreement across all the three coders was satisfactory (0.88). Discrepancies among the three coders were resolved and consensus was finally reached. Saturation of categories was well-examined.

For an overview, the data analysis was captured by the data structure as shown in Figure 1.

Figure 1. Data Structure

Second-order themes

Aggregate dimensions

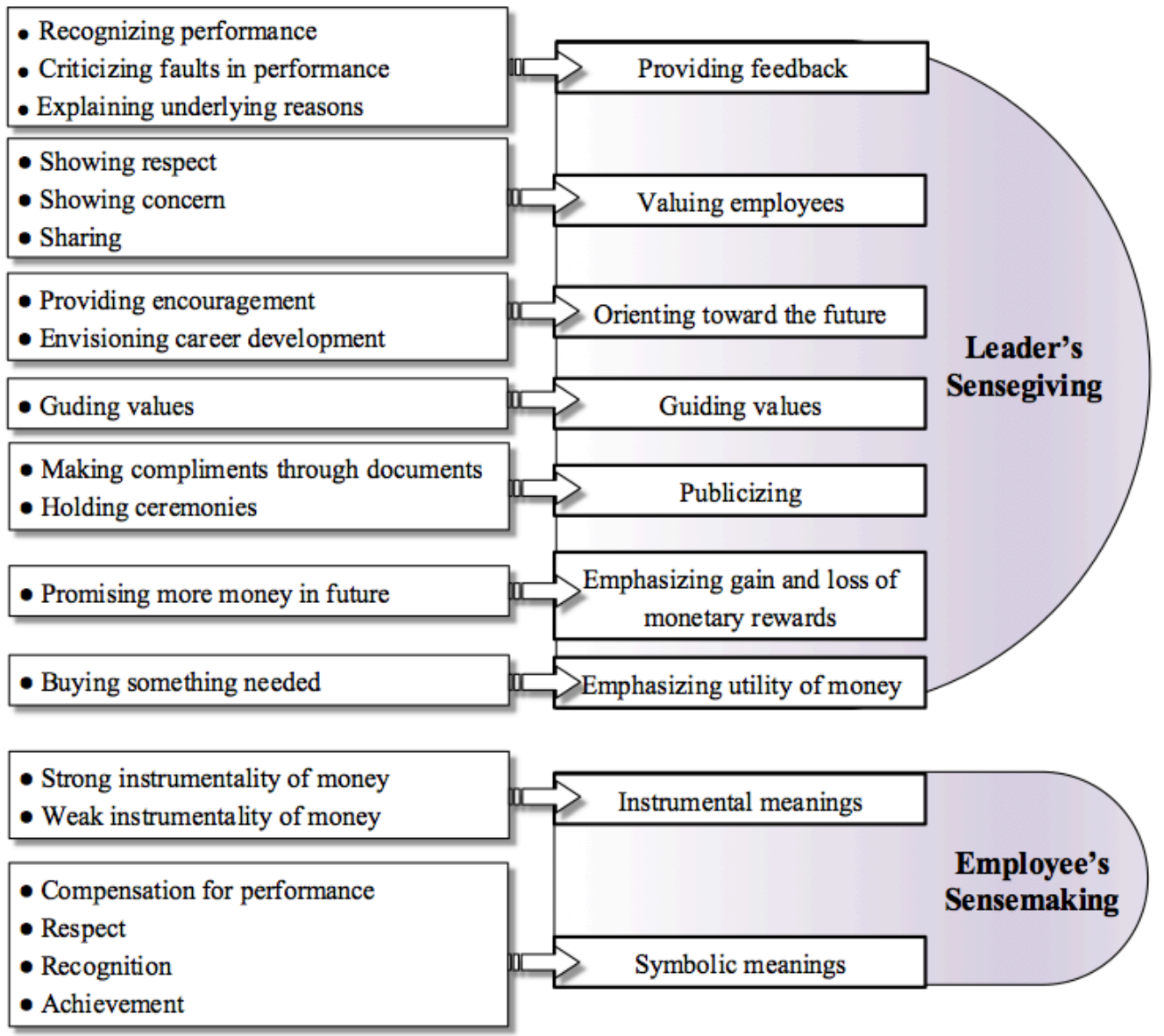

\section{RESULTS}

\section{Leader Sensegiving in Distribution Processes}

Table 1 presents the leader's sensegiving behaviors and statements in the distribution process. It should be noted that not all sensegiving processes lead to the construction of symbolic meanings. Thus, the sensegiving processes were 
distinguished into two sub-categories: sensegiving with and without symbolic meanings. It was found that leader's sensegiving without symbolic meanings included the emphasis on gain/loss of monetary rewards and utility of money, labeled as "money-oriented sensegiving strategies." "Emphasis on gain/loss of monetary rewards" indicated that when employees received their monetary rewards, leaders would point out their mistakes instead of recognizing their accomplishments or promising monetary rewards if the employees performed well in the future. "Emphasizing on utility of money" indicated that leaders highlight the instrumental value of monetary rewards.

Meanwhile, leader's sensegiving with symbolic meanings included providing feedback, valuing employees, orienting toward the future, and publicizing. Providing feedback includes recognizing performance and explaining underlying reasons. Valuing employees includes showing respect, concern, and sharing through which leaders convey meanings such as sincere caring and respect for workers. For example, when one of the respondents received an allowance for a business trip, the leader emphasized the importance of safety. Guiding values means that leaders communicate their beliefs and values to employees to guide their perceptions of work and performance. Orienting toward the future refers to the situation in which leaders describe the future career development of employees and encourage them to pursue such goals when distributing monetary rewards. Publicizing means that leaders construct meaning by distributing the reward in public, such as sending a notice to all employees in one company to award individual work performance. Promising more money in the future means that leaders describe desirable future monetary gains to help mitigate the negative effects of the current situation.

Table 1. Sensegiving strategies in the distribution processes

\begin{tabular}{|c|c|c|}
\hline $\begin{array}{l}\text { Aggregate } \\
\text { dimensions }\end{array}$ & Second-order themes & Quotes \\
\hline $\begin{array}{l}\text { Emphasizing gain/loss } \\
\text { of monetary rewards }\end{array}$ & Promising more money in the future & $\begin{array}{l}\text { "The project manager promised that we would still get } \\
\text { money if we perform well next year." }(+) \\
\text { "They said that I would receive more after becoming a } \\
\text { permanent employee next year." }(*)\end{array}$ \\
\hline $\begin{array}{l}\text { Emphasizing utility of } \\
\text { money }\end{array}$ & Buying something needed & $\begin{array}{l}\text { "Congratulations for being economically independent. Now } \\
\text { that the weather is hot, you can buy an air-conditioning } \\
\text { unit." }(+) \\
\text { "As the New Year Festival is coming, you can buy anything } \\
\text { you want with this year's rewards." (+) }\end{array}$ \\
\hline \multirow[t]{3}{*}{ Providing feedback } & Recognizing performance & $\begin{array}{l}\text { "I was in charge of a training program, and the leader } \\
\text { praised me that we saved the company's money and got } \\
\text { the good results, when he sent me the rewards. He } \\
\text { recognized my expertise in training." ( }+ \text { ) } \\
\text { "Once we got the final rewards after finishing a key project, } \\
\text { the manager praised our performance results and hoped } \\
\text { we work hard later." }(+)\end{array}$ \\
\hline & Criticizing faults in performance & $\begin{array}{l}\text { "We got lots of money, but the department manager } \\
\text { commented the faults in our work." }(+)\end{array}$ \\
\hline & Explaining underlying reasons & $\begin{array}{l}\text { "Business efficiency was low, so only a part of our wages } \\
\text { was given." }(*) \\
\text { "The salary of the production department is often higher } \\
\text { than that of the functional department." }(*)\end{array}$ \\
\hline \multirow{3}{*}{ Valuing employees } & Showing respect & $\begin{array}{l}\text { "When I worked no more than two years, I solved one } \\
\text { system problem in a key project. The leader thanked me } \\
\text { for my excellent work and he also called at } 3 \text { A.M } \\
\text { concerning about the executed situation when it was first } \\
\text { launched on line." ( }+)\end{array}$ \\
\hline & Showing concern & $\begin{array}{l}\text { "When you are out of town on a business trip, if you are late } \\
\text { for the train, just find some place to stay if you miss the } \\
\text { train. Your safety is most important." ( }+)\end{array}$ \\
\hline & Sharing & $\begin{array}{l}\text { "If the company is fine, everyone will be fine. The goal of } \\
\text { our company is for everyone to have a house and a car." } \\
(+)\end{array}$ \\
\hline
\end{tabular}

(Table 1 continued on next page) 
(Table 1 continued)

\begin{tabular}{|c|c|c|}
\hline $\begin{array}{c}\text { Aggregate } \\
\text { dimensions }\end{array}$ & Second-order themes & Quotes \\
\hline Guiding values & Guiding values & $\begin{array}{l}\text { "When we got the champion within organizational } \\
\text { competition, the leader told us that your work attitude is } \\
\text { very important, and sometimes, we just need to insist on } \\
\text { when you feel you cannot." ( }+ \text { ) } \\
\text { "Consider your contribution to the company rather than } \\
\text { what you can get from it." }(*) \\
\text { "Let me work temporally from the administration } \\
\text { department to the front-line plant, and distributing me } \\
\text { with lower-position rewards. The manager told me that as } \\
\text { the front-line experience is very important, I should work } \\
\text { step by step, and I should eat up little by little." }(*)\end{array}$ \\
\hline \multirow{2}{*}{ Orienting future } & Envisioning career development & $\begin{array}{l}\text { "When I got the annual excellent employee rewards at my } \\
\text { first year working in the company, the leader discussed } \\
\text { with me my career prospects and his expectations for } \\
\text { me." (+) }\end{array}$ \\
\hline & Providing encouragement & $\begin{array}{l}\text { "When our leader provided me the rewards, he expected me } \\
\text { to make persistent efforts in the future." }(+) \\
\text { "The manager told me to work harder next month, and then } \\
\text { I can get my expected salary." }(*)\end{array}$ \\
\hline \multirow{2}{*}{ Publicizing } & Making documents & $\begin{array}{l}\text { "At the end of the year, I got technical innovation rewards } \\
\text { as well as the special rewards, and the leader prepared one } \\
\text { praise letter in the company's name and send it out to all } \\
\text { of us." (+) }\end{array}$ \\
\hline & Holding ceremonies & $\begin{array}{l}\text { "As an annual excellent employee, I was singled out at the } \\
\text { Quarterly Conference." ( }+) \\
\text { "I was appraised at the Commending Conference together } \\
\text { with our general manager." ( }+)\end{array}$ \\
\hline
\end{tabular}

\section{Sensemaking of Employee Recipients of Monetary Rewards}

Table 2 presents the sensemaking of employee recipients including instrumental and symbolic meanings of monetary rewards. The strong instrumentality indicated that the employees could obtain a large amount of money to purchase things they need, whereas it is the opposite in case of weak instrumentality. The symbolic meanings of monetary rewards included recognition, respect, compensation for performance, and achievement. When leader's sensegiving was present, the meanings of monetary reward were more relevant to the symbolic meanings $(68.2 \%)$, whereas the instrumental meanings were less endorsed (31.8\%). In contrast, when the monetary rewards were distributed without leader's sensegiving, the symbolic meanings of the monetary rewards were largely reduced, and the meanings of monetary rewards primarily fell into the category of the instrumentality of money $(65.5 \%)$.

In the pleasant distribution processes (254 of 291 incidents), the sensemaking of monetary rewards of employees included both instrumental and symbolic meanings. Of 163 incidents, 153 mentioned receipt of a great amount of money. In 10 pleasant distribution processes, recipients mentioned receiving a small amount of money. On the other hand, in the unpleasant distribution processes, there were mostly the instrumental meanings of monetary rewards including strong and weak instrumentality of money and no symbolic meanings were found. Recipients were seldom satisfied with the amount of monetary rewards and stressed that "The amount of money was too small to spend". Of 128 reported incidents, 117 received a small amount of money. In 11 unpleasant distribution processes, although employees received a large amount of money, the distribution processes were perceived as unpleasant. This paradox may be explained by delayed distribution (seven incidents), too much taxing (one incident), unfairness (one incident), and lack of positive symbolic meanings (two incidents). 
Table 2. Employees' sensemaking in the distribution processes

\begin{tabular}{|c|c|c|}
\hline Aggregate dimensions & Second-order themes & Quotes \\
\hline \multirow[t]{2}{*}{ Instrumental meanings } & Strong instrumentality of money & $\begin{array}{l}\text { "I got the salary for the first time as a formal employee, I } \\
\text { can spend the money I earned by myself and buy what I } \\
\text { want." ( }+ \text { ) } \\
\text { "I received the annual rewards, and the quantity was } \\
\text { large. It seemed that I can buy lot of things." ( }+)\end{array}$ \\
\hline & Weak instrumentality of money & $\begin{array}{l}\text { "The amount of money was too small to spend." }(*) \\
\text { "We got too few amount of rewards after we kept no } \\
\text { accident record more than } 1,000 \text { days." }(*)\end{array}$ \\
\hline \multirow{5}{*}{ Symbolic meanings } & Compensation for performance & $\begin{array}{l}\text { "Once I joined in one key project, after we completed it } \\
\text { on time, I got the rewards. My hard work was } \\
\text { rewarded." ( }+ \text { ) } \\
\text { "After we worked hard for the whole year, we got what } \\
\text { we the company promised us." }(+)\end{array}$ \\
\hline & Respect & $\begin{array}{l}\text { "After we hardly finished the program, our company sent } \\
\text { all of us a special reward. Although the amount of } \\
\text { money was small, we felt that we were valued." }(+) \\
\text { "Our company endowed me with the general manager's } \\
\text { special award at the whole company's annual meeting." } \\
(+)\end{array}$ \\
\hline & Recognition & $\begin{array}{l}\text { "When I got the highest level of the annual rewards, I felt } \\
\text { that I was recognized and my ability was noticed." ( }+ \text { ) } \\
\text { "After we accomplished the training program by } \\
\text { ourselves, we got a great amount of special rewards for } \\
\text { our excellent work." }(+)\end{array}$ \\
\hline & Achievement & $\begin{array}{l}\text { "After our team solved the technical problem } \\
\text { independently, we got the technology awards, and this } \\
\text { gave me a sense of achievement." ( }+ \text { ) } \\
\text { "Because our program brought about the considerable } \\
\text { profits for our company, I got the program rewards and } \\
\text { it made me feel very proud of our performance." }(+)\end{array}$ \\
\hline & Unfairness & $\begin{array}{l}\text { "The distribution decision was completely made by the } \\
\text { department head who favored someone else." }(*) \\
\text { "All the new comers distributed the same amount of } \\
\text { money, neither considering about the differences } \\
\text { among the individual's competence or hard-working } \\
\text { attitudes." }(*)\end{array}$ \\
\hline
\end{tabular}

$(+)$ : refer to "in the pleasant distribution"; $(*)$ : refer to "in the unpleasant distribution processes"

\section{DISCUSSION}

\section{Theoretical Implications}

The study provides convincing evidence that employee perceptions about money are influenced by a leader's behaviors and statements when distributing monetary rewards. This research has three major theoretical contributions to the literatures on monetary rewards, leadership, sensegiving and sensemaking.

\section{Contributions to the Literature on Monetary Rewards}

The present research is among the first attempts to systematically explore how monetary rewards can obtain meanings through the interplay of a leader's sensegiving and an employee recipient's sensemaking during the distribution process of monetary rewards. This study advances prior knowledge at least in two ways.

First, the findings provide direct empirical support for the occurrence of both instrumental and symbolic meanings of monetary rewards. On the one hand, the results confirmed that the instrumental value of monetary rewards, which is consistent with the traditional knowledge regarding the employees receiving money, seems to be instrumental in 
fulfilling their material desires (Child, 2015). The instrumental meaning of monetary rewards provide emprical support for the fourth dimension of spending posited by the compensation theory of pay (Thierry, 1992). Moreover, it has been shown that the amount of money determines whether it has a strong or weak instrumentality, echoing the importance of pay level in affecting employee attitudes and behaviors (Gardner, Dyne \& Pierce, 2004). On the other hand, the findings revealed that the symbolic values of monetary rewards included signaling recognition, respect, compensation for performance, and valuing achievement. These findings provided direct empirical evidence for the core idea of the compensation theory of pay, which states that the salience of pay is determined by the meanings of pay, such as motivational properties, relative position, and control (Thierry, 1992). In addition, these findings also supported the theorization of Salimäki et al. (2009), which argues that pay could imbue meanings to one's self-identity.

Second, the prior knowledge was deepened by revealing that symbolic meanings of monetary rewards play a more influential effect on perception of money than the instrumental meanings of monetary rewards. As monetary rewards are the primary and ubiquitous mean of motivating and compensating employees, most economic research focuses on financial rewards (Prendergast, 1999). In addition, one major research line emphasized on the critical roles of nonmonetary factors, such as job meaning (Kosfeld et al. 2014) and non-monetary rewards (Waqas \& Saleem, 2014) in motivating individuals. The study provided a new angle to understand how monetary rewards themselves could motivate employees via employee sensemaking of monetary rewards. The findings provided direct evidence on the importance of the symbolic value of money, which has long been negelected in the literature. In different situations, the same amount of monetary rewards showed different meanings for employees. The study lends supportive evidence to the argument that people do not experience "all dollars as the same" (Thaler, 1999) and differentiates the symbolic meanings of money with its instrumental meanings.

\section{Contributions to the Literature on Leadership}

Although the influence of leaders on the meaning of rewards (Salimäki et al. 2009) was emphasized upon, the major focus was on the leader's role in implementing pay system (Beer et al. 2004), the ways in which the leaders administered monetary rewards, and their impact on employees' internal cognitive processes (Podsakoff, Bommer, Podsakoff \& MacKenzie, 2006). It has been argued that as immediate supervisors holding the leadership position can affect processes through which the individual pay is determined. This research, as an initial attempt, extends prior work by highlighting the role of leader's sensegiving strategies in engendering instrumental and symbolic meanings of monetary rewards perceived by employee recipients.

The findings revealed that leader's sensegiving strategies influenced the employee's perceptions of monetary rewards during the distribution process. Specifically, the leaders used different flexible sensegiving strategies when distributing rewards. The first two sensegiving strategies - emphasis on gain/loss of monetary rewards and utility of money - labelled as "Money-oriented sensegiving strategies", highlights the strong instrumentality of money without generating symbolic meanings. The following five sensegiving strategies focus on employee performance and competence, and show concern for employees, including providing feedback, valuing employees, guiding values, orienting future, and publicizing, which arelabelled as "Non-money-oriented sensegiving strategies." As Lawler (1971) proposed that pay is expected to satisfy the personal needs and motives, the present study substantiated this proposal by showing that money provides meanings of security or living, recognition by peers, and status in his or her professional group.

By revealing the two extreme distribution processes (pleasant vs. unpleasant), the qualitative study further showed that the leaders used more types of sensegiving strategies in the pleasant distribution process than they did in the unpleasant process. These findings suggested that to avoid the employee's unpleasant experience about the monetary rewards, there is a need for leaders to adopt more effective sensegiving strategies, such as recognizing employee performance to satisfy their need for competence, and valuing employees to show respect and showing concern for employee affection. This idea is highly consistent with the self-determination theory (Deci \& Ryan, 2000), which posits that humans have innate psychological needs for competence, autonomy, and relatedness. The present study also supports Armstrong's (2007) viewpoint that employees do work for money but for meaning in their lives.

Contributions to the Literature on Sensegiving and Sensemaking

Most of the earlier studies on sensegiving and sensemaking have been conducted in the organizational change context. 
This research is among the first to apply the perspectivs of sensegiving and sensemaking to the content of the distribution process of monetary rewards. As an initial step, this research shows that leader's sensegiving is likely to send messages about the meanings of monetary rewards, and in doing so, to affect employee's sensemaking of the monetary rewards. Importantly, the study revealed the role of leader's sensegiving in influencing the symbolic meanings of monetary rewards perceived by employee recipients in the distribution process. Thus, this study shows that sensegiving and sensemaking theories could be applied in ambiguous or uncertain contexts of daily organization life, which also encourages future research to apply these theories into other important organizational contexts.

\section{Practical Implications}

This study offers a number of practical implications. The findings revealed that the symbolic meanings of monetary rewards can be generated by the sensegiving statements and behaviors of leaders, and provide practical implications for the importance of the motivational significance of monetary rewards. The study extends prior pratical implications that primarily focus on how to enrich job and improve work-life quality in motivating employees (Child, 2015). Organizations should design training programs for leaders to learn how to exhibit sensegiving behaviors in distributing monetary rewards. Under these training programs, leaders learn the ways to guide their employees.

First, leaders can be trained to provide performance feedback to employees in the distribution process of monetary rewards and make money more valuable. Aguinis et al. (2013) proposed that managers should provide a specific and accurate explanation regarding why an employee is being rewarded. Once the employees receive monetary rewards, leaders should seize the opportunities to explain why they get the rewards, how things are progressing, and whether they have questions or need help. In addition, employees are more likely to repeat desired behaviors if they have a specific and accurate understanding of why they received a reward (Aguinis, 2013). It has also been found that the contingency of rewards and performance percieved by the employees drives them to exert the extent of effort (Trevor, Reilly \& Gerhart, 2012).

Second, leaders can be trained to show respect and care for employess via distributing monetary rewards. Employees would make sense of monetary rewards received such that the reception of monetary rewards reflects how the leaders and organizations care about their work and lives. Consistent with organizational support theory (Rhoades \& Eisenberger, 2002), employees' acceptance of favorable treatment from a supervisor contributes to the perceived organizational support, thereby elevating perceived obligation to care about the organization's welfare and contribute to the organization in reaching its objectives.

Third, leaders can be trained to provide employees with a vision of the future while distributing monetary rewards. Future vision, such as new promotion opportunities, the chance to gain new skills and experience, the value of the job and personal achievement, is important for employees in interpreting the meanings of monetary rewards. Monetary rewards can improve employee motivation and performance because they can satisfy a wide range of low- and highlevel needs (Long \& Shields, 2010). The compensation literature (Rynes, Gerhart \& Parks, 2005) emphasized that money has an impact on "lower-order needs" (such as shelter and food) and paves the way for fulfilling "higher-order needs" (such as achievement and self-realization). Individual need differences may function as a moderating variable for employees high on lower-order needs, who tend to make sense of monetary rewards to be instrumental values. For those high on higher-order needs, they are likely to value monetary rewards as signaling symbolic values. This symbolic role of monetary rewards is similar to inspirational motivation, a subdimension of transformational leadership, or the degree to which leaders articulate visions that appeal to followers (Bass, Avolio, Jung \& Berson, 2003). When leaders engage in inspirational motivation, followers may view their jobs as more significant and meaningful (Nielsen \& Daniels, 2012) and prefer to pursue higher-order needs, therefore, showing high motivation and exhibiting high levels of performance. 


\section{Limitations and Future Research Directions}

In this study, we were unable to measure the extent of leader sensegiving and employee sensemaking based on the qualitative method. Future research is recommended to adopt quantitative methods to assess the levels of sensemaking and sensegving, and examine their effects on employee's attitude and performance outcome.

Meanwhile, the present study was conducted in Chinese context. Hence, issue of the generalizability of the findings might be a concern. Although the theorization is not tied to any cultural differences, it is valuable to see whether there are cultural contingencies that influence leader's sensegiving and employee's sensemaking in the distribution process of monetary rewards. Specifically, we expect that materialism would play a role in affecting how employee make sense of monetary rewards they receive. Money is important and taking on a critical role in China (Johansson, 2001) because of the high level of materialism in the Chinese context (Inglehart, 1997). The employees with high materialistic values are likely to emphasize on the instrumental meanings of monetary rewards. Another cultural factor may be power distance. As China is high on power distance (Hofstede, 1980), Chinese employees high on power distance orientation are expected to accept unequal power, respect and trust their leader (Kirkman, Chen, Farh, Chen \& Lowe, 2009). Hence, in our Chinese context, when leaders provide sensegiving strategies in distributing monetary rewards, employees are likely to be alert to and respect for their leader's sensegiving behaviors and statements. In other words, leader's sensegiving would exert a stronger effect on employee's sensemaking of monetary rewards received in a high-power distance context. Hence, future research to investigate the influence of cultural factors is highly encouraged.

In addition, the number of critical incidents obtained was relatively small and may be not sufficient in the unpleasant distribution process, thereby limiting the understanding of unknown phenomena involved. One promising future research direction may compare the effects of sensegiving carried out by leaders from different managerial positions.

Finally, it is unclear that how different communication media adopted by leaders during monetary distribution processes, such as face-to-face, e-mail, telephone, or a combination of different methods would affect employees' sensemaking of monetary rewards. Media richness theory (Daft \& Lengel, 1984; 1986) posits that leaders select different media for communicative tasks, dependent on the richness of medium and the equivocality of the task. Faceto-face would be the "richest" medium because leaders can provide specific sensegiving behaviors and give immediate feedback, especially when monetary distribution processes are equivocal and unclear to their employees. In this case, employees may interpret monetary rewards with instrumental and symbolic meanings. A leaner communication medium, such as email and telephone, can be used when incentive polices are relatively clear and transparent to employees. We expect that the use of this type of communication medium will be more efficient and provide more instrumental meanings but less symbolic meanings as compared to the use of face-to-face medium. We encourage future research to test these possibilities.

\section{CONCLUSION}

The myth of monetary rewards has received much research attention since decades. The present research explores how employee's sensemaking of monetary rewards spring from leader's sensegiving strategies in monetary distribution processes. The current study takes an important step towards understanding how to make money valuable and highlights the role of leaders in eliciting the values of money.

\section{AUTHOR BIOGRAPHIES}

Yufan Shang is a professor in School of Management, Xi'an Jiaotong University. She received her Ph.D. in Management from Xi'an Jiaotong University. Her research interest is leadership development in organizations. She has published academic articles in journals such as the International Journal of Human Resource Management and Chinese Management Studies.

Jun Xu is a Ph.D. candidate in School of Management, Xi'an Jiaotong University. Her research interests cover leadership and creativity. 
Fuli Li is a professor in School of Management, Xi'an Jiaotong University. She received a joint $\mathrm{PhD}$ degree in management from City University of Hong Kong and University of Science and Technology of China. Her current research interests include creativity, cross-cultural psychology, and research methodology. She has published academic articles in journals such as Personnel Psychology, Journal of Organizational Behavior, Organizational Research Methods, Journal of Cross-Cultural Psychology, and Journal of Business Psychology.

Xinyu Zhao is a Ph.D. candidate in School of Management, Xi'an Jiaotong University. His research interests cover leadership, leader power and creativity.

Haiyun Li is a graduate student in School of Management, Xi' an Jiaotong University.

\section{REFERENCES}

Aguinis, H. (2013). Performance Management (3rd ed.). UpperSaddle River, NJ: Pearson Prentice Hall.

Aguinis, H., Joo, H., \& Gottfredson, R. K. (2013). What monetary rewards can and cannot do: How to show employees the money. Business Horizons, 56(2), 241-249.

Armstrong, M. (2007). Organisation and People Employee Reward. Broadway Wimbledon: CIPD publishers.

Ashforth, B. E., Harrison, S. H., \& Corley, K. G. (2008). Identification in organizations: An examination of four fundamental questions. Journal of Management, 34(3), 325-374.

Bass, B. M., Avolio, B. J., Jung, D. I., \& Berson, Y. (2003). Predicting unit performance by assessing transformational and transactional leadership. Journal of Applied Psychology, 88(2), 207-218.

Beer, M., Cannon, M. D., Baron, J. N., Dailey, P. R., Gerhart, B., Heneman, H. G., Kochan, T., Ledford Jr, G. E., \& Locke, E. A. (2004). Promise and peril in implementing pay-for-performance. Human Resource Management, 43(1), 3-48.

Charmaz, K. (2014). Constructing Grounded Theory. London: Sage.

Child, J. (2015). Organization: Contemporary Principles and Practice. Chichester: John Wiley \& Sons.

Christ, M. H., Sedatole, K. L., Towry, K. L., \& Thomas, M. A. (2008). When formal controls undermine trust and cooperation. Strategic Finance, 89(7), 39-44.

Daft, R. L., \& Lengel, R. H. (1984). Information richness: A new approach to managerial behavior and organizational design. In B. Staw \& L. L. Cummings (Eds). Research in Organizational Behavior (Vol. 6, pp.191-233). Greenwich, CT: JAI.

Daft, R. L., \& Lengel, R. H. (1986). Organizational information requirements: Media richness and structural design. Management Science, 32, 554-571.

Deci, E. L., Koestner, R., \& Ryan, R. M. (1999). A meta-analytic review of experiments examining the effects of extrinsic rewards on intrinsic motivation. Psychological Bulletin, 125(6), 627-668.

Deci, E. L., \& Ryan, R. M. (2000). The" what" and" why" of goal pursuits: Human needs and the self-determination of behavior. Psychological Inquiry, 11(4), 227-268.

Drake, A. R., Wong, J., \& Salter, S. B. (2007). Empowerment, motivation, and performance: Examining the impact of feedback and incentives on nonmanagement employees. Behavioral Research in Accounting, 19(1), 71-89.

Edvardsson, B. (1992). Service breakdowns: A study of critical incidents in an airline. International Journal of Service Industry Management, 3(4), 17-29.

Elo, S., \& Kyngäs, H. (2008). The qualitative content analysis process. Journal of Advanced Nursing, 62(1), 107-115.

Furnham, A., \& Argyle, M. (1998). The Psychology of Money. London: Routledge.

Gardner, D. G., Dyne, L., \& Pierce, J. L. (2004). The effects of pay level on organization-based self-esteem and performance: A field study. Journal of Occupational and Organizational Psychology, 77(3), 307-322.

Gioia, D. A., \& Chittipeddi, K. (1991). Sensemaking and sensegiving in strategic change initiation. Strategic Management Journal, 12(6), 433-448.

Gioia, D. A., Corley, K. G., \& Hamilton, A. L. (2013). Seeking qualitative rigor in inductive research notes on the Gioia methodology. Organizational Research Methods, 16(1), 15-31.

Gremler, D. D. (2004). The critical incident technique in service research. Journal of Service Research, 7(1), 65-89.

Hakonen, A., Hulkko, K., \& Maaniemi, J. (2006). The meaning of results oriented pay and its effects on individual performance. In P. Malmberg (Ed.), Scientific Proceedings of the European Productivity Conference (Vol. 6, pp. 122-128). Espoo, Finland.

Harris, J., \& Bromiley, P. (2007). Incentives to cheat: The influence of executive compensation and firm performance on financial misrepresentation. Organization Science, 18(3), 350-367.

Hofstede, G. (1980). Motivation, leadership, and organization: do American theories apply abroad? Organizational dynamics, $9(1), 42-63$.

Inglehart, R. (1997). Modernization and Post-Modernization: Cultural, Economic, and Political Change in 43 Societies. Princeton, NJ: Princeton University Press. 
Jenkins Jr, G. D., Mitra, A., Gupta, N., \& Shaw, J. D. (1998). Are financial incentives related to performance? A meta-analytic review of empirical research. Journal of Applied Psychology, 83(5), 777-787.

Johansson, P. (2001). Selling the "modern woman": Consumer culture and Chinese gender politics. In S. Munshi (Ed.), Images of the "Modern Woman" in Asia: Global Media, Local Meanings (pp. 94-121). London: Routledge.

Kassarjian, H. H. (1977). Content analysis in consumer research. Journal of Consumer Research, 4(1), 8-18.

Kirkman, B. L., Chen, G., Farh, J.-L., Chen, Z. X., \& Lowe, K. B. (2009). Individual power distance orientation and follower reactions to transformational leaders: A cross-level, cross-cultural examination. Academy of Management Journal, 52(4), 744-764.

Kosfeld, M., Neckermann, S., \& Yang, X. (2014). Knowing that you matter, matters! The interplay of meaning, monetary incentives, and worker recognition. ZEW-Centre for European Economic Research Discussion Paper, pp. 14-097.

Lawler, E. (1971). Pay and Organization Effectiveness: A Psychological View. New York, NY: McGraw Hill.

Long, R. J., \& Shields, J. L. (2010). From pay to praise? Non-cash employee recognition in Canadian and Australian firms. The International Journal of Human Resource Management, 21(8), 1145-1172.

Maitlis, S., \& Christianson, M. (2014). Sensemaking in organizations: Taking stock and moving forward. The Academy of Management Annals, 8(1), 57-125.

Maitlis, S., \& Lawrence, T. B. (2007). Triggers and enablers of sensegiving in organizations. Academy of Management Journal, 50(1), 57-84.

Mickel, A. E., \& Barron, L. A. (2008). Getting “more bang for the buck" symbolic value of monetary rewards in organizations. Journal of Management Inquiry, 17(4), 329-338.

Mitchell, T. R., \& Mickel, A. E. (1999). The meaning of money: An individual-difference perspective. Academy of Management Review, 24(3), 568-578.

Nelms, T. C., \& Maurer, B. (2014). Materiality, symbol, and complexity in the anthropology of money. In E. Bijleveld, \& H. Aarts (Eds.), The Psychological Science of Money (pp. 37-70). New York: Springer.

Nielsen, K., \& Daniels, K. (2012). Does shared and differentiated transformational leadership predict followers' working conditions and well-being? The Leadership Quarterly, 23(3), 383-397.

Podsakoff, P. M., Bommer, W. H., Podsakoff, N. P., \& MacKenzie, S. B. (2006). Relationships between leader reward and punishment behavior and subordinate attitudes, perceptions, and behaviors: A meta-analytic review of existing and new research. Organizational Behavior and Human Decision Processes, 99(2), 113-142.

Prendergast, C. (1999). The provision of incentives in firms. Journal of Economic Literature, 37(1), 7-63.

Rhoades, L., \& Eisenberger, R. (2002). Perceived organizational support: A review of the literature. Journal of Applied Psychology, 87(4), 698-714.

Rynes, S. L., Gerhart, B., \& Parks, L. (2005). Personnel psychology: Performance evaluation and pay for performance. Annual Review of Psychology, 56(1), 571-600.

Salimäki, A., Hakonen, A., \& Heneman, R. L. (2009). Managers generating meaning for pay: A test for reflection theory. Journal of Managerial Psychology, 24(2), 161-177.

Thaler, R. H. (1999). Mental accounting matters. Journal of Behavioral Decision Making, 12(3), 183-206.

Thierry, H. (1992). Payment:" Which meanings are rewarding?". The American Behavioral Scientist, 35(6), 694-707.

Trevor, C. O., Reilly, G., \& Gerhart, B. (2012). Reconsidering pay dispersion's effect on the performance of interdependent work: Reconciling sorting and pay inequality. Academy of Management Journal, 55(3), 585-610.

Waqas, Z., \& Saleem, S. (2014). The effect of monetary and non-monetary rewards on employee engagement and firm performance. European Journal of Business and Management, 6(31), 73-82.

Weick, K. E. (1995). Sensemaking in Organizations. London: Sage. 